\title{
THE EFFECTS OF SUPERVISOR WORK-FAMILY SUPPORT ON INDIGENOUS EMPLOYEES: A STUDY OF JOB AND HEALTH OUTCOMES
}

\author{
David Brougham \\ Waikato Management School \\ University of Waikato \\ Professor Jarrod Haar \\ School of Business \\ Massey University
}

\begin{abstract}
Support from work and non-work sources is highly important for employee well-being and job outcomes. However, few studies have explored social support from both domains. Furthermore, workplace studies on indigenous employees are severely under researched. Based on survey data from 260 Māori (the indigenous people of New Zealand) employees, we conducted analysis using structural equation modeling, to test supervisor work-family support (SWFS) and whānau (extended family) support towards well-being and job outcomes. Overall, findings show that SWFS and whānau support both predict job satisfaction and emotional exhaustion, while SWFS also directly predicts turnover intentions. In turn, job satisfaction significantly predicts all outcomes: our study shows that it mediates the influence of support on outcomes. Findings indicate that support from both work and home (extended family) is likely to be highly beneficial towards the broad range of job outcomes investigated for Māori employees, especially through enhancing job satisfaction.
\end{abstract}

\section{Introduction}

This study tested social support from both work and nonwork sources. Testing both forms of support simultaneously has received limited attention in academic research (Adams, King, \& King, 1996; Lapierre \& Allen, 2006). Like many other developed Western countries, New Zealand has undergone many changes that have affected the work-family interface, e.g., more dual earning couples, longer working hours and a shift of employee values (Aryee, Chu, Kim, \& Ryu, in press; Greenhaus \& Powell, 2006; Ministry of Social Development, 2009; Ng, Eby, Sorensen, \& Feldman, 2005; Statistics New Zealand, 2008). Because of the negative impacts these changes have had on employees' health and job outcomes, organizations need to develop strategies to manage employee work-family issues (Allen \& Armstrong, 2006; Eby, Casper, Lockwood, Bordeaux, \& Brinley, 2005; Frone, Russell, \& Cooper, 1997; Kossek, 2005).

Offering organizational support and formal work-family policies/benefits has been recognized as an effective means of improving employee well-being and job outcomes (Allen, 2001; Bagger \& Li, in press), however the lack of supervisor support may mitigate the success of these initiatives (Aryee et al., in press; Bagger \& Li, in press). Supervisors are often referred to as gate keepers and linking pins to the successful implementation of both formal and informal work-family support (Hammer, Kossek, Zimmerman, \& Daniels, 2007; Ryan \& Kossek, 2008). Furthermore, the level of support from a supervisor towards an employee's family concerns is a stronger predictor of work-family conflict than other forms of support (Kossek, Pichler, Bodner, \& Hammer, 2011). Therefore, the benefits of SWFS should be considered when looking at effective ways for employees to manage their busy lives and the associated fallout that may result from undertaking multiple roles.

The present study focuses on Māori as they are under researched in the workplace, make up a significant part of the workforce (Haar \& Brougham, 2011, in press), and are an integral part of the workforce (Brougham, 2011). Recent census data shows the majority of the population within New Zealand is European, 67.6 per cent of the population, while 14.6 per cent of people within New Zealand identify as Māori (Statistics New Zealand, 2007a). Understanding that Māori have significantly different needs to the European majority may be a significant factor in improving employee outcomes. 
Given New Zealand's diverse nature, managers need to be proactive in understanding and supporting the differing work-family needs of their employees (Brougham, 2011). Within New Zealand, whānau has been found to play an important role in the outcomes of Māori employees (Haar, Roche, \& Taylor, 2011), but as an employee group, Māori are still under researched. Whānau support is included in the present study because of the complex family relationships Māori have with immediate and extended family. This inclusion of both whānau support and SWFS answers calls from Lapierre and Allen (2006) who suggested that understanding one's family and supervisor is a promising area for reducing work-family conflict and increasing the well-being for employees.

The present study makes several contributions to the literature: (1) for the first time, we test support from both supervisor and family (whānau) within an indigenous employee population; (2) we respond to calls in the literature to examine a broader range of well-being outcomes (Hammer, Kossek, Yragui, Bodner, \& Hanson, 2009) by including job and well-being outcomes in the present study; and (3) we respond to Bagger and Li (in press), and test and find support for job satisfaction as a mediator of support to outcomes and provide better understanding of the complex relationships between support and outcomes.

\section{Previous Research}

Given the many changes to work and family over the past 30-40 years, exploring the dynamics of support from both work and non-work sources may be highly important in understanding employee well-being and job outcomes (Hammer et al., 2009; Lapierre \& Allen, 2006). Social support theory is typically used to explain the different forms of support and how they operate, as it is viewed as an antecedent in predicting, and buffering, the effects of stress, general health and well-being (Adams et al., 1996; Beehr, King, \& King, 1990; Carlson \& Perrewé, 1999; House, 1981; Lakey \& Cohen, 2000). Cobb (1976) defined social support as "information leading the subject to believe that he is cared for and loved, esteemed, and a member of a network of mutual obligations" (p. 300). While social support takes many forms (Carlson \& Perrewé, 1999), the present study focuses on social support from a work source (i.e., SWFS) and a non-work source (i.e., whānau support).

SWFS is a type of workplace social support which is similar to social support as it reflects the "the degree to which individuals perceive that their well-being is valued by workplace sources, such as supervisors and the broader organization in which they are embedded and the perception that these sources provide help to support this well-being” (Kossek et al., 2011, p. 292). While there are several other terms to describe this type of support, e.g., Family-Supportive Supervision (Foley, Linnehan, Greenhaus, \& Weer, 2006; Lapierre \& Allen, 2006), Supervisory Family Support (Bagger \& Li, in press), and Family-Supportive Supervisor Behaviours (FSSB) (Hammer et al., 2007), fundamentally, they capture a similar construct. We use SWFS to represent this construct which is consistent with terminology used in a recent meta-analysis by Kossek et al. (2011).

Thomas and Ganster (1995) suggested that supervisors who support work-family issues "empathize with the employee's desire to seek balance between work and family responsibilities” (p. 7). Kossek (2011) stated that "supervisor work-family support is defined as perceptions that one's supervisor cares about an individual's work-family well-being, demonstrated by supervisory helping behaviors to resolve work-family conflicts” (p. 291). Examples of SWFS are: expressions of concern (e.g., emotional support), allowing employees to have a flexible schedule, the ability to take personal phone calls at work and pick children up from school during work hours (Aryee et al., in press; Kossek, Barber, \& Winters, 1999; Kossek et al., 2011; Thomas \& Ganster, 1995). In addition, if a company does have formal polices to assist with the management of work-family issues, for example, flex-time or working from home; it is often the supervisor who enables the employee's successful utilization of these policies (Bagger \& Li, in press). This type of informal support (Hammer et al., 2007) is considered important in the workplace (Kossek et al., 1999; Thompson, Beauvais, \& Lyness, 1999). Overall, when support is high employees "should be motivated to give something extra back to their organization in return for extra benefits" (Lambert, 2000, p. 802) and will have improved levels of health and well-being (Carlson \& Perrewé, 1999).

The present study suggests that SWFS will be particularly important and beneficial to Māori given that a New Zealand Government study showed Māori reported the lowest levels of work-family balance compared to both the majority group (Europeans) and other minority groups (Ministry of Social Development, 2008). There are several reasons for this, including Māori occupying lower skilled positions (Department of Labour, 2009; TPK, 2009), and engaging in long work hours and shift work (Statistics New Zealand, 2008). Māori also have a lower average income than New Zealand Europeans (Statistics New Zealand, 2007b) and, combined, these statistics support Verkuyten's (2008) statement that being within a minority group generally equates to a "lower income, lower education and poorer health” (p. 391).

Aryee et al. (in press) suggested that researchers are moving away from formal work-family policies, to focus instead on informal assistance given to work-family needs. The importance of supervisor support on the workfamily relationship was reinforced with a meta-analysis by Kossek et al. (2011) that drew data from 115 samples from 85 studies, with a combined sample size of over 72 thousand employees. Results indicated that "supervisor work-family support had a direct and negative relationship towards work-to-family conflict” (Kossek et al., 2011, p. 303). These findings link with other studies highlighting the benefits of SWFS, including being positively linked to job satisfaction (Bagger \& $\mathrm{Li}$, in press; Frye \& Breaugh, 2004; Hammer et al., 2009; Thomas \& Ganster, 1995) and negatively linked to turnover intentions (Bagger \& Li, in press; Hammer et al., 2009; Thompson et al., 1999). O'Driscoll et al. (2003) 
found that supervisor support could also moderate (buffer) the effects of work-family conflict towards strain. Overall, it is expected that employees who are supervised by managers who are supportive towards work and family, are likely to benefit through enhanced job outcomes and well-being (Hammer et al., 2007).

Hammer et al. (2009) stated that "further research should also examine a broader array of outcomes" (p. 853) and encouraged extending the influence of SWFS towards worker health and well-being outcomes. In response to Hammer et al. (2009), the present study tests a broad range of outcomes as follows.

Hypothesis 1: SWFS will be positively related to (a) job satisfaction, and negatively related to (b) turnover intentions, (c) insomnia, (d) emotional exhaustion, and (e) cynicism.

\section{Family and Whānau Support}

As discussed above, non-work sources such as family support are a form of social support, and can play a significant role in predicting health and well-being outcomes (Adams et al., 1996; Viswesvaran et al., 1999) as well as job outcomes (King, Mattimore, King, \& Adams, 1995). For example, one's spouse or family can provide support in times of crisis (Hupcey, 1998). Researchers are beginning to focus on non-work related forms of support (e.g., Bishop, Scott, Goldsby, \& Cropanzano, 2005); with Lapierre and Allen (2006) suggesting that family support is a promising area of support research.

We argue that family support is likely to be very important for Māori as they hold fundamentally different world views from New Zealand Europeans with respect to family connections. Specifically, Māori have a higher value on "relationality, collectivity, reciprocity, and connectivity to prior generations" (Hook, 2007, p. 4). Whereas, New Zealand Europeans tend to value "autonomy, freedom, self-interest, entitlement, competition” (Hook, 2007, p. 4). Durie (1997) suggested that whānau (extended family) is "based on a common whakapapa (descent from a shared ancestor), and within which certain responsibilities and obligations are maintained" (p. 1). Those within a whānau form a cohesive unit working towards the same goals, through group solidarity, warm interpersonal interactions and cheerful cooperation (Bishop, 2005). The connection that Māori place on their family networks and linkages with others, called whanaungatanga (Haar \& Delaney, 2009), is also strengthened through whānau ties and responsibilities (Durie, 1997), further highlighting the importance of whānau and its related support for working Māori.

We expected that Māori employees would have a greater focus and responsibility towards family (Haar et al., 2011) and thus gain many benefits from whānau support. Whānau support can include education, guidance and financial support in times of crisis (Durie, 1997). Overall, whānau support captures the "much wider and inter- generational conceptualization of family" (Haar et al., 2011, p. 2551) for Māori.

The literature shows that social support from non-work sources, such as family, is likely to have a significant effect on well-being (Adams et al., 1996). Walen and Lachman (2000) found family support was positively related to life satisfaction, positive mood, and health, and negatively to strain and negative moods. Similarly, Lu (1999) found family support negatively related to anxiety and depression outcomes.

Furthermore, family support can also influence job outcomes. Baruch-Feldman, Brondolo, Ben-Dayan, and Schwarz (2002) found family support was a significant predictor of job satisfaction (positively) and job burnout (negatively). They noted "there has been much less research on the association of family support to job satisfaction" (p. 85), highlighting the need to test the effect of distinct sources of support on different job outcomes. In his meta-analysis, Halbesleben (2006) found that family support was significantly linked to all dimensions of job burnout. Studies have found that family support is positively related to job satisfaction (King et al., 1995; Adams et al., 1996), and that family support is significantly and positively related to both pay satisfaction and job satisfaction (Lu, 1999).

Um and Harrison (1998) found links between social support (including family support) and job and well-being outcomes. In a New Zealand context, Haar et al. (2011) found a significant and negative link between whānau support and turnover intentions within a sample of Māori employees. Studies such as that of Haar et al. (2011) validate this study's testing of whānau support's link with the broad range of job outcomes identified in this study.

While researchers (Adams et al., 1996; King et al., 1995) suggest that family support is likely to have a stronger influence on well-being outcomes than job outcomes, given the cultural importance of whānau for Māori, following previous research we suggest that family support will have beneficial links to all tested outcomes. This leads to our second hypothesis.

Hypotheses 2: Whānau support will be positively related to (a) job satisfaction, and negatively related to (b) turnover intentions, (c) insomnia, (d) emotional exhaustion, and (e) cynicism.

\section{Mediating Effects}

Finally, we respond to Bagger and Li's (in press) statement that a "complete understanding of the mediating mechanism is critical for the advancement of research on supervisory family support" (p. 2) and we extend this required understanding to include SWFS. A meta-analysis by Faragher et al. (2005) found job satisfaction to be a significant predictor of outcomes: people with higher job satisfaction were more likely to experience lower levels of job burnout, anxiety and depression. We expect job satisfaction to have similar effects on the well-being outcomes selected (i.e., 
emotional exhaustion, cynicism and insomnia). Furthermore, a meta-analysis by Griffeth, Hom and Gaertner (2000) found that job satisfaction is a strong predictor of turnover intentions. Overall, SWFS is a consistent predictor of job satisfaction (e.g., Bagger \& Li, in press; Frye \& Breaugh, 2004; Hammer et al., 2009; Thomas \& Ganster, 1995), and family support relates to job satisfaction (King et al., 1995; Adams et al., 1996; Lu, 1999; Baruch-Feldman, 2002). Thus, the mediating effects of job satisfaction were explored.

Overall, there is strong evidence (Faragher et al., 2005; Griffeth et al., 2000) that job satisfaction may mediate the influence of support from supervisors and whānau towards the outcomes tested here. As such, we argue that support from work and non-work sources will ultimately enhance job satisfaction, and this in turn will have a beneficial influence on other outcomes, specifically reducing mental health outcomes and turnover intentions. This leads to our final hypothesis:

Hypothesis 3: Job satisfaction will mediate the relationship between SWFS and whānau support towards (a) turnover intentions, (b) insomnia, (c) emotional exhaustion, and (d) cynicism.

\section{Method}

\section{Sample and Procedure}

Data was collected from a wide range of New Zealand organizations. Purposeful sampling was carried out to specifically attract responses from Māori employees within these 100 organizations. Surveys were distributed and data was collected in two waves, with a one month time lag to reduce the chances of common method variance. Surveys were matched with unique employee codes. Survey one contained measured SWSF, whānau support, and demographic variables, while survey two measured job satisfaction, turnover intentions, emotional exhaustion, cynicism, and insomnia.

From a total of 500 Māori employees, 260 participants responded to both surveys (52\% response rate). On average, the participants were 39 years old $(\mathrm{SD}=11.7$ years), married (67\%), parents (70\%), and female (65\%). Respondents worked 40.1 hours per week ( $\mathrm{SD}=9.8$ hours) and had job tenure of 5.7 years ( $S D=7.1$ years), with 19 per cent holding a high school qualification, 13 per cent a technical college qualification, 44 per cent a university degree, and 24 percent a postgraduate qualification. Forty six percent of respondents worked in an organization that had a major focus on Māori, for example Māori health or education. A T-test confirmed there were no significant differences between the responses of participants working for Māori organizations and non-Maori organizations. Finally, respondents were predominately from the public sector (70\%), followed respectively by the private sector (23\%) and not-for-profit (7\%).

\section{Measures}

\section{Predictor variables}

Supervisor work-family support was measured using five items by Lambert (2000), coded 1 = strongly disagree, 5 = strongly agree. A sample question is: "My supervisor... is helpful to me when I have a routine family or personal matter to attend to". This measure has been validated in New Zealand by Haar and Roche (2008) with $\alpha=0.88$. The present study found $\alpha=0.93$. Whānau support was measured using three items from Haar et al. (2011), coded 1 = strongly disagree, $5=$ strongly agree. A sample question is: "My whānau help out when there is a family or personal emergency". Haar et al. (2011) reported $\alpha=$ .75 , the present study finds $\alpha=.83$

\section{Mediator variable}

Job Satisfaction was measured using three items from Judge, Bono, Erez and Locke (2005). A sample question is: "Most days I am enthusiastic about my work" ( $\alpha=$ 0.76).

\section{Criterion variables}

Turnover Intentions was measured using three items from Kelloway, Gottlieb, and Barham (1999), coded $1=$ strongly disagree, $5=$ strongly agree. A sample question is: "I am thinking about leaving my organization" $(\alpha=$ 0.89). Emotional Exhaustion was measured using four items from Maslach and Jackson (1981), coded 1 = never, 5 = always. A sample question is: "I feel emotionally drained from my work” $(\alpha=0.90)$. Cynicism was also measured using four items from Maslach and Jackson (1981), coded 1 = never, 5 = always, and a sample question is: "I have become more cynical about whether my work contributes anything” ( $\alpha=0.85)$. Insomnia was measured using three items from Greenberg (2006), coded $1=$ not at all, 5 = to a great extent agree. Questions followed the stem: "Indicate the extent to which you have experienced each of the following symptoms over the past month" with a sample item being: "Difficulty falling asleep" $(\alpha=0.88)$.

\section{Measurement Models}

Many studies using structural equation modelling (SEM) typically offer a number of goodness-of-fit indexes. However, Williams, Vandenberg and Edwards (2009) argued that some goodness-of-fit indexes e.g., chi-square, have become less useful. They suggested the use of the following three goodness-of-fit indexes as superior ways to assess model fit: (1) the comparative fit index (CFI $>$.95), (2) the root-mean-square error of approximation (RMSEA < .08), and (3) the standardized root mean residual (SRMR <.10). The hypothesized measurement model and two alternative models are shown in Table 1. 


\begin{tabular}{|c|c|c|c|c|c|c|c|c|c|}
\hline \multirow[b]{2}{*}{ Model } & \multicolumn{4}{|c|}{ Model Fit Indices } & \multicolumn{5}{|c|}{ Model Differences } \\
\hline & $\chi^{2}$ & df & $\mathbf{C F I}$ & RMSEA & SRMR & $x^{2}$ & $\Delta \mathrm{df}$ & $\mathbf{p}$ & Details \\
\hline $\begin{array}{l}\text { 1. Hypothesized 7-factor model: Job } \\
\text { Satisfaction, Tumover Intertions, } \\
\text { Emotional Exhaustion, Cyricism, } \\
\text { Insomnia, SWFS and Whānau Support. }\end{array}$ & 463.5 & 254 & .95 & .06 & .05 & & & & \\
\hline $\begin{array}{l}\text { 2. Altemative } 6 \text {-factor model Job } \\
\text { Satisfaction, Tumover Intentions, } \\
\text { Emotional Exhaustion, Cyricism, } \\
\text { Insomnia, and SWFS and Whānau Support } \\
\text { combined. }\end{array}$ & 764.1 & 260 & .88 & .09 & .08 & 300.6 & 6 & .001 & $\begin{array}{l}\text { Model } \\
2 \text { to } 1\end{array}$ \\
\hline $\begin{array}{l}\text { 3. Altemative } 5 \text {-factor model: Job } \\
\text { Satisfaction, Tumover Intentions, and } \\
\text { Emotional Exhaustion, Cyricism, and } \\
\text { Insomnia combined, SWFS and Whānau } \\
\text { Support. }\end{array}$ & 995.3 & 265 & .83 & .10 & .07 & 531.8 & 11 & .001 & $\begin{array}{l}\text { Model } \\
3 \text { to } 1\end{array}$ \\
\hline
\end{tabular}

The hypothesized measurement model was the best fit to the data. We confirmed this best fit through testing two alternative measurement models, which resulted in both models being a worse fit. Following guidelines by Hair, Black, Babin and Anderson (2010), these comparison models were all significantly different (all $\mathrm{p}<$.001) and a poorer fit than the hypothesized model.

\section{Analysis}

Hypotheses were tested using SEM in AMOS to assess the direct and mediational effects of the study variables.
Analysis showed that control variables related to demographics (e.g., gender), work variables (e.g., tenure), and non-work variables (e.g., family size) did not change the nature of effects found, and thus we did not include any control variables in the final models.

\section{Results}

Table 2 illustrates the descriptive statistics for the present study.

\section{TABLE 2. Descriptive Statistics and Correlations}

\begin{tabular}{|c|c|c|c|c|c|c|c|c|c|}
\hline Variables & $\mathrm{M}$ & SD & 1 & 2 & 3 & 4 & 5 & 6 & 7 \\
\hline 1. Job Satisfaction & 3.8 & .75 & - & & & & & & \\
\hline 2. Tumover Intentions & 2.9 & 1.1 & $-44^{* *}$ & - & & & & & \\
\hline 3. Emotional Exhaustion & 2.4 & 99 & $-32 * *$ & $30 * *$ & - & & & & \\
\hline 4. Cynicism & 2.2 & 96 & $-.55^{* *}$ & $.50 * *$ & $64 * *$ & - & & & \\
\hline 5. Insomria & 2.4 & 1.1 & $-32 * *$ & $33^{* *}$ & $61^{* *}$ & $47^{* *}$ & - & & \\
\hline 6. SWFS & 4.0 & .80 & $33^{* *}$ & $-35 * *$ & $-.25 * *$ & $-31^{* *}$ & $-20 * *$ & $\ldots$ & \\
\hline 7. Whānau Support & 3.9 & .79 & $19^{* *}$ & -.09 & $-.19 * *$ & $-16^{*}$ & $-.18^{* *}$ & $18^{* *}$ & $=$ \\
\hline
\end{tabular}

$\mathrm{N}=260 * \mathrm{p}<.05, * * \mathrm{p}<.01$

Table 2 shows nearly all outcome variables were significantly correlated with each other (all $\mathrm{p}<.01$ ).

Using the approach of Hair et al. (2010), we tested comparison models and found that model 3 (partial mediation model) was superior to the other models (direct direct effects model (Figure 1) and the partial mediation model (Figure 2), which allows us to compare the additional benefits of including job satisfaction as a mediator. 
$\underline{\text { Figure 1. Direct Effects Model }}$
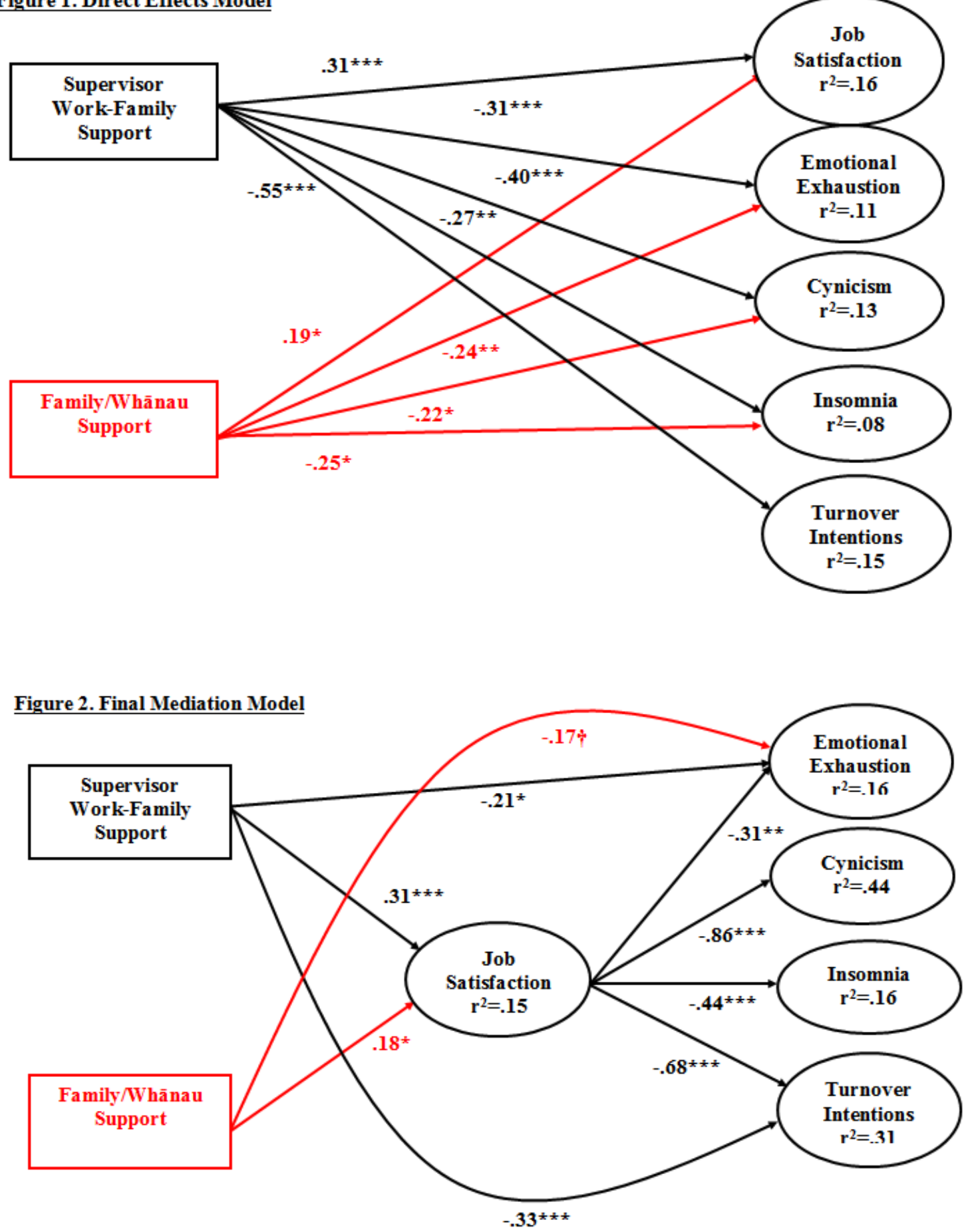

\section{Structural Models}

Aligned with the recommendations of Grace and Bollen (2005), unstandardized regression coefficients are presented in Figures 1 and 2. We see from Figure 1 that SWFS is significantly linked with job satisfaction (path coefficient $=0.31, \mathrm{p}<0.001$ ), emotional exhaustion (path coefficient $=-0.31, \mathrm{p}<0.001$ ), cynicism (path coefficient $=-0.40, \mathrm{p}<0.001$ ), insomnia (path coefficient $=-0.27, \mathrm{p}$ $<0.001$ ), and turnover intentions (path coefficient = $0.55, \mathrm{p}<0.001$ ). From Figure 1, we also see that whānau support is significantly linked with job satisfaction (path coefficient $=0.19, \mathrm{p}<0.05$ ), emotional exhaustion (path coefficient $=-0.24, \mathrm{p}<0.01$ ), cynicism (path coefficient $=-0.22, \mathrm{p}<0.05$ ), and insomnia (path coefficient $=-0.25$, $\mathrm{p}<0.05$ ).

Figure 2 (mediation study) shows that SWFS is significantly linked with job satisfaction (path coefficient $=0.31, \mathrm{p}<0.001$ ) as is whānau support (path coefficient $=0.18, \mathrm{p}<0.05)$. Job satisfaction is significantly linked with emotional exhaustion (path coefficient $=-0.31, \mathrm{p}<$ 0.001 ), cynicism (path coefficient $=-0.86, \mathrm{p}<0.001$ ), insomnia (path coefficient $=-0.44, \mathrm{p}<0.001$ ), and 
turnover intentions (path coefficient $=-0.68, \mathrm{p}<0.001$ ). In addition, there are two direct effects with SWFS being significantly linked to emotional exhaustion (path coefficient $=-0.21, \mathrm{p}<0.05$ ) and turnover intentions (path coefficient $=-0.33, \mathrm{p}<0.001$ ), while whānau support is significantly linked to emotional exhaustion (path coefficient $=-0.17, \mathrm{p}<0.057$ ).

The model shows that the support dimensions account for a modest amount of variance towards job satisfaction (15\%). By comparing Figures 1 and 2, we can see that large amounts of variance towards outcomes are due to the mediator (job satisfaction). Support and job satisfaction account for 16 per cent the variance for emotional exhaustion (increased from 11\%), 44 per cent for cynicism (increased from 13\%), 16 per cent for insomnia (increased from 8\%), and 31 per cent of turnover intentions (increased from 15\%). Overall, job satisfaction as a mediator accounted for significantly more variance than inclusion of the two support dimensions alone.

\section{Discussion}

Research surrounding social support theory suggests that support from work and non-work related sources is likely to be highly beneficial to the individual (Adams et al., 1996; Carlson \& Perrewé, 1999). As such, we tested support from supervisors (work-related social support) and whānau (non-work social support) on a sample of Māori employees. Adams et al. (1996) suggested that testing support from both workplace and family sources was under researched; a concern repeated a decade later by Lapierre and Allen (2006) who suggested this was still a promising area of research. Given the importance of whānau in providing benefits for Māori people (Durie, 1997); the effects of whānau support were also tested towards the same range of job and well-being outcomes as SWFS.

Our direct effects model shows that SWFS predicts job satisfaction, turnover intentions, insomnia, emotional exhaustion, and cynicism in the expected direction. Similarly, whānau support is also a strong predictor of all tested outcomes, excluding turnover intentions. Results from the study suggest that SWFS and whānau support are important predictors of Māori employee job and wellbeing outcomes. We now discuss our mediation model in detail and the implications for management.

Given the need to have a greater understanding of the complexities of relationships regarding social support and outcomes (Bagger \& $\mathrm{Li}$, in press), SEM was used to test for potential mediation effects. Findings suggest that a mediation model was superior to the direct effects model. However, SFWS and whānau support still had direct effects on some outcomes, highlighting the applicability of a partial mediation model. For instance, SWFS was found to have a significant relationship with turnover intentions for our sample of Māori employees, which is consistent with other research (Anderson, Coffey, \& Byerly, 2002; Thomas \& Ganster, 1995). SWFS also had a direct effect on emotional exhaustion, which adds further understanding to the currently limited understanding of SWFS and employee well-being (Hammer et al., 2009). Whānau support also had direct effects on emotional exhaustion, consistent with social support theory which suggests that family is likely to have a beneficial effect on health and well-being (Adams et al., 1996).

Our mediation model (Figure 2) revealed that job satisfaction plays a powerful mediator role between the other outcomes, SFWS and whānau support. According to Adams et al (1996), social support from work related sources (i.e., SWFS) is more likely to predict job related outcomes (i.e., job satisfaction) over and above non-work related sources (i.e., whānau support). This is consistent with our results, which show SWFS as a stronger predictor of job satisfaction (path coefficient $=0.31, \mathrm{p}<$ .001 ) than whānau support (path coefficient $=0.19, \mathrm{p}<$ $.05)$, although whānau support was still a significant predictor. Furthermore, job satisfaction had a significant negative effect on emotional exhaustion, cynicism, insomnia, and turnover intentions, supporting the mediation hypothesis. These findings support metaanalyses that highlight job satisfaction as being a significant predictor of similar well-being outcomes, such as job burnout (Faragher et al., 2005) and turnover intentions (Griffeth et al., 2000).

Despite having a lesser effect than SWFS in our model, whānau support is still highly beneficial, and has significant direct effects on job satisfaction. This is not surprising considering King et al. (1995) stated that "it is logical that family social support would be more highly related to life satisfaction than to job satisfaction since family members are typically removed from the work setting” (p. 241). However, this finding does the ability of family support to predict job related outcomes (King et al., 1995; Adams et al., 1996; Lu, 1999; Baruch-Feldman, 2002). Our results supplement findings from Haar et al. (2011), which highlighted the benefits of whānau support towards job outcomes for Māori employees. Overall, our findings suggest that employees with high level of support from their supervisors and whānau are likely to have greater job satisfaction, which is, in turn, likely to have a beneficial effect on job satisfaction and wellbeing.

Māori respondents in our sample reported a high level of support from their supervisors and whānau, which is positive. This is highly important considering the Ministry of Social Development (2008) reported that "Māori had the lowest rate of satisfaction with work-life balance" (p. 55) compared to other ethnic groups within New Zealand. Furthermore, Foley (2006) suggested that employees that were racially dissimilar to their supervisor would in general have less support. While the present study did not test the ethnicity of the supervisors, we suggest the high SWFS score is a positive within our sample, suggesting that Māori feel well supported by their supervisors towards work-family issues. We believe that the degree of supervisor support is likely to be highly important to Māori given the discretion supervisors have in enabling employees to attend family matters, such as a tangi (a Māori funeral that can last several days), during 
work. Māori, as a markedly different race to the hegemonic, European, majority have distinct needs, due in part to the complex range of their social connections (Hook, 2007), and are therefore more likely to experience conflict between work and family (Haar et al., 2011). This paper endorses calls from Haar et al. (2011) who stated that "European New Zealanders must come to understand Māori perspectives in order to properly support Māori employees to reach their potential" (p. 2556). The data collected for this paper indicate that this understanding, and subsequent support, appears to be strong, both within the workplace and in the broader family context.

\section{Implications for Managers}

The present study underscores the importance of SWFS and whānau for indigenous and minority groups working within a Western working environment. The findings also offer several implications for managers. Consistent with Bagger and $\mathrm{Li}$ (in press) we suggest that supporting employees "makes good business sense. . . [and will] ultimately contribute favourably to the bottom line" (p. 22) and may create a competitive advantage (Aryee et al., in press). The ability for supervisors to manage employees in a way that meets their cultural needs (Ramamoorthy \& Carroll, 1998) is important considering the level of diversity within both New Zealand (Khawaja, Boddington, \& Didham, 2007) and other countries (Cox, 1991).

Understanding the differences between cultures in the workplace is important given that previous research has shown that managers are more likely to support employees that are ethnically similar to themselves (Foley et al., 2006). Training managers to be more supportive and understanding towards general work-family needs has been discussed by researchers (e.g. Aryee et al., in press; Hammer, Kossek, Anger, Bodner, \& Zimmerman, 2011; Hammer et al., 2007). We suggest that training managers to understand cultural differences (e.g., customs and beliefs) may be advantageous considering the positive results gained from training managers to be more supportive in Hammer et al's (2011) quasi-experiment. Kossek et al. (1999) argued that supervisors need to be the leaders when changing the culture of an organization to be more supportive towards employees.

\section{Limitations}

Despite the strengths of the present study, there are some limitations to acknowledge such as the use of selfreported data, and only exploring on ethnic group within New Zealand.

\section{References}

Adams, G. A., King, L. A., \& King, D. W. (1996). Relationships of job and family involvement, family social support, and work-family conflict with job and life satisfaction. Journal of Applied Psychology, 81(4), 411-420.
Allen, T. (2001). Family-supportive work environments: The role of organizational perceptions. Journal of Vocational Behavior, 58(3), 414-435.

Allen, T. D., \& Armstrong, J. (2006). Further examination of the link between work-family conflict and physical health. American Behavioral Scientist, 49(9), 1204-1221.

Anderson, S. E., Coffey, B. S., \& Byerly, R. T. (2002). Formal organizational initiatives and informal workplace practices: Links to work-family conflict and job-related outcomes. Journal of Management, 28(6), 787-810.

Aryee, S., Chu, C. W. L., Kim, T., \& Ryu, S. (in press). Family-supportive work environment and employee work behaviors: An investigation of mediating mechanisms. Journal of Management, 1-22. doi: $10.1177 / 0149206311435103$

Bagger, J., \& Li, A. (in press). How does supervisory family support influence employees' attitudes and behaviors? A social exchange perspective. Journal of Management, 1-28. doi: $10.1177 / 0149206311413922$

Baruch-Feldman, C., Brondolo, E., Ben-Dayan, D., \& Schwarz, J. (2002). Sources of social support and burnout, job satisfaction, and productivity. Journal of Occupational Health Psychology, 7(1), 84-93.

Beehr, T. A., King, L. A., \& King, D. W. (1990). Social support and occupational stress: Talking to supervisors. Journal of Vocational Behavior, 36(1), 61-81.

Bishop, J. W., Scott, K. D., Goldsby, M. G., \& Cropanzano, R. (2005). A construct validity study of commitment and perceived support variables. Group \& Organization Management, 30(2), 153-180.

Bishop, R. (2005). Freeing ourselves from neocolonial domination in research: A Kaupapa Maori approach to creating knowledge. In N. K. Denzin \& Y. S. Lincoln (Eds.), The sage handbook of qualitative research (3rd ed.) (pp. 109-138). Thousands Oaks, CA: Sage.

Brougham, D. (2011). When the minority becomes the majority: The implications of New Zealand's changing demographics. New Zealand Journal of Human Resource Management, 11(2), 78-89.

Carlson, D. S., \& Perrewé, P. L. (1999). The role of social support in the stressor-strain relationship: An examination of work-family conflict. Journal of Management, 25(4), 513-540.

Cobb, S. (1976). Presidential Address-1976. Social support as a moderator of life stress. Psychosomatic Medicine, 38(5), 300-314. 
Cox, T. (1991). The multicultural organization. The Executive, 5(2), 34-47.

Department of Labour. (2009). Maori in the New Zealand labour market. Wellington, New Zealand: Department of Labour.

Durie, M. (1997). Whānau, whanaungatanga and healthy Maori development. In P. Te Whāiti \& $\mathrm{M}$. McCarthy (Eds.), Mai i Rangiātea (pp. 1-24). Auckland, New Zealand: Auckland University Press.

Eby, L. T., Casper, W. J., Lockwood, A., Bordeaux, C., \& Brinley, A. (2005). Work and family research in IO/OB: Content analysis and review of the literature (1980-2002). Journal of Vocational Behavior, 66(1), 215-232.

Faragher, E. B., Cass, M., \& Cooper, C. L. (2005). The relationship between job satisfaction and health: A meta-analysis. Occupational and Environmental Medicine, 62(2), 105-112.

Foley, S., Linnehan, F., Greenhaus, J. H., \& Weer, C. H. (2006). The impact of gender similarity, racial similarity, and work culture on family-supportive supervision. Group \& Organization Management, 31(4), 420-441.

Frone, M. R., Russell, M., \& Cooper, M. L. (1997). Relation of work-family conflict to health outcomes: A four-year longitudinal study of employed parents. Journal of Occupational and Organizational Psychology, 70(4), 325-335.

Frye, N. K., \& Breaugh, J. A. (2004). Family-friendly policies, supervisor support, work-family conflict, family-work conflict, and satisfaction: A test of a conceptual model. Journal of Business and Psychology, 19(2), 197-220.

Greenberg, J. (2006). Losing sleep over organizational injustice: Attenuating insomniac reactions to underpayment inequity with supervisory training in interactional justice. Journal of Applied Psychology, 91(1), 58-69.

Greenhaus, J. H., \& Powell, G. N. (2006). When work and family are allies: A theory of work-family enrichment. The Academy of Management Review, 31(1), 72-92.

Griffeth, R. W., Hom, P. W., \& Gaertner, S. (2000). A meta-analysis of antecedents and correlates of employee turnover: Update, moderator tests, and research implications for the next millennium. Journal of Management, 26(3), 463-488.

Haar, J. M., \& Brougham, D. (2011). Consequences of cultural satisfaction at work: A study of New Zealand Maori. Asia Pacific Journal of Human Resources, 49(4), 461-475.
Haar, J. M., \& Brougham, D. (in press). An indigenous model of career satisfaction: Exploring the role of workplace cultural wellbeing. Social Indicators Research. doi: 10.1007/s11205-011-9962-y

Haar, J. M., Roche, M., \& Taylor, D. (2011). Workfamily conflict and turnover intentions of indigenous employees: The importance of the whanau/family for Maori. The International Journal of Human Resource Management, 23(12), 2546-2560. doi: 10.1080/09585192.2011.610344

Haar, J., \& Delaney, B. (2009). Entrepreneurship and maori cultural values: Using 'Whanaungatanga' to understanding Maori business. New Zealand Journal of Applied Business Research, 7(1), 25-40.

Haar, J., \& Roche, M. (2008). Employee perceptions of organisational support for workfamily issues and outcomes: The moderating effects of supervisor support. New Zealand Journal of Human Resources Management, 8, 1-27.

Hair, J. F., Black, W. C., Babin, B. J., \& Anderson, R. E. (2010). Multivariate data analysis (7th ed.). New York, NY: Pearson Prentice Hall.

Halbesleben, J. R. (2006). Sources of social support and burnout: A meta-analytic test of the conservation of resources model. Journal of Applied Psychology, 91(5), 1134-1145.

Hammer, L. B., Kossek, E. E., Anger, W. K., Bodner, T., \& Zimmerman, K. L. (2011). Clarifying work-family intervention processes: The roles of work-family conflict and family-supportive supervisor behaviors. Journal of Applied Psychology, 96(1), 134-150.

Hammer, L. B., Kossek, E. E., Yragui, N. L., Bodner, T. E., \& Hanson, G. C. (2009). Development and validation of a multidimensional measure of family supportive supervisor behaviors (FSSB). Journal of Management, 35(4), 837-856.

Hammer, L. B., Kossek, E. E., Zimmerman, K., \& Daniels, R. (2007). Clarifying the construct of family supportive supervisory behaviors (FSSB): A multilevel perspective. Research in Occupational Stress and Well-being, 6, 171-211.

Hook, G. (2007). A future for Māori education part II: The reintegration of culture and education. MAI Review, 1, 1-17.

House, G. S. (1981). Work stress and social support. Reading, MA: Addison-Wesley.

Hupcey, J. E. (1998). Clarifying the social support theory research linkage. Journal of Advanced Nursing, 27(6), 1231-1241.

Judge, T. A., Bono, J. E., Erez, A., \& Locke, E. A. (2005). Core self-evaluations and job and life satisfaction: The role of self-concordance and goal 
attainment. Journal of Applied Psychology, 90(2), 257-268.

Kelloway, E., Gottlieb, B., \& Barham, L. (1999). The source, nature, and direction of work and family conflict: A longitudinal investigation. Journal of Occupational Health Psychology, 4(4), 337-346.

Khawaja, M., Boddington, B., \& Didham, R. (2007). Growing ethnic diversity in New Zealand and its implications for measuring differentials in fertility and mortality. Wellington, New Zealand: Statistics New Zealand.

King, L. A., Mattimore, L. K., King, D. W., \& Adams, G. A. (1995). Family support inventory for workers: A new measure of perceived social support from family members. Journal of Organizational Behavior, 16(3), 235-258.

Kossek, E. E. (2005). Workplace policies and practices to support work and families. In S. Bianchi, L. Casper \& R. King (Eds.), Work, family, health, and well-being (pp. 97-116). Mahwah, NJ: Erlbaum Press.

Kossek, E. E., Barber, A. E., \& Winters, D. (1999). Using flexible schedules in the managerial world: The power of peers. Human Resource Management, 38(1), 33-46.

Kossek, E. E., Pichler, S., Bodner, T., \& Hammer, L. B. (2011). Workplace social support and workfamily conflict: A meta-analysis clarifying the influence of general and work-family-specific supervisor and organizational support. Personnel Psychology, 64(2), 289-313.

Lakey, B., \& Cohen, S. (2000). Social support theory and measurement. In S. Cohen, L. Underwood \& B. Gottlieb (Eds.), Social support measurement and intervention: A guide for health and social scientists (pp. 29-52). Toronto: Oxford University Press.

Lambert, S. J. (2000). Added benefits: The link between work-life benefits and organizational citizenship behavior. Academy of Management Journal, 43(5), 801-815

Lapierre, L. M., \& Allen, T. D. (2006). Worksupportive family, family-supportive supervision, use of organizational benefits, and problemfocused coping: Implications for work-family conflict and employee well-being. Journal of Occupational Health Psychology, 11(2), 169-181.

Lu L. (1999). Work motivation, job stress and employees' well-being. Journal of Applied Management Studies, 8(1), 61-72.

Maslach, C., \& Jackson, S. E. (1981). The measurement of experienced burnout. Journal of Occupational Behaviour, 2(2), 99-113.
Ministry of Social Development. (2008). The social report 2008: Te purongo oranga tangata 2008. Wellington, New Zealand: Ministry of Social Development.

Ministry of Social Development. (2009). The social report. Wellington, New Zealand: The Ministry of Social Development.

Ng, T., Eby, L., Sorensen, K., \& Feldman, D. (2005). Predictors of objective and subjective career success: A meta analysis. Personnel Psychology, 58(2), 367-408.

O'Driscoll, M. P., Poelmans, S., Spector, P. E., Kalliath, T., Allen, T. D., Cooper, C. L., et al. (2003). Family-responsive interventions, perceived organizational and supervisor support, workfamily conflict, and psychological strain. International Journal of Stress Management, 10(4), 326-344.

Ramamoorthy, N., \& Carroll, S. (1998). Individualism/collectivism orientations and reactions toward alternative human resource management practices. Human Relations, 51(5), $571-588$

Ryan, A. M., \& Kossek, E. E. (2008). Work-life policy implementation: Breaking down or creating barriers to inclusiveness? Human Resource Management-New York, 47(2), 295-310.

Statistics New Zealand. (2007a). QuickStats about culture and identity. Wellington, New Zealand: Statistics New Zealand.

Statistics New Zealand. (2007b). QuickStats about incomes. Wellington, New Zealand: Statistics New Zealand.

Statistics New Zealand. (2008). Survey of Working Life: March 2008 quarter. Wellington, New Zealand: Statistics New Zealand.

Thomas, L. T., \& Ganster, D. C. (1995). Impact of family-supportive work variables on work-family conflict and strain: A control perspective. Journal of Applied Psychology, 80(1), 6-15.

Thompson, C. A., Beauvais, L. L., \& Lyness, K. S. (1999). When work-family benefits are not enough: The influence of work-family culture on benefit utilization, organizational attachment, and work-family conflict. Journal of Vocational Behavior, 54(3), 392-415.

TPK. (2009). Māori Employment by Occupation. Wellington, New Zealand: Te Puni Kokiri (Ministry of Maori Development).

Um, M.Y., \& Harrison, D.F. (1998). Role stressors, burnout, mediators, and job satisfaction: A stressstrain-outcome model and an empirical test. Social Work Research, 22(2), 100-115. 
Verkuyten, M. (2008). Life satisfaction among ethnic minorities: The role of discrimination and group identification. Social Indicators Research, 89(3), 391-404.

Viswesvaran, C., Sanchez, J. I., \& Fisher, J. (1999). The role of social support in the process of work stress: A meta-analysis. Journal of Vocational Behavior, 54(2), 314-334.

Walen, H. R., \& Lachman, M. E. (2000). Social support and strain from partner, family, and friends: Costs and benefits for men and women in adulthood. Journal of Social and Personal Relationships, 17(1), 5-30.

Williams, L., Vandenberg, R., \& Edwards, J. (2009). 12 structural equation modeling in management research: A guide for improved analysis. The Academy of Management Annals, 3(1), 543-604. 